\title{
El tratamiento de las marcas de colores en la jurisprudencia del Tribunal de Justicia de la Comunidad Andina ${ }^{1}$
}

The treatment of colour trademarks in the jurisprudence of the Andean Court of Justice

\section{Juan Manuel Indacochea Jauregui}

jmindacochea@gmail.com

Colaborador de la Magistratura del Perú en el Tribunal de Justicia de la Comunidad Andina. Ex Consultor interno de la Magistratura de Bolivia del Tribunal de Justicia de la Comunidad Andina. Master en Derecho Internacional en la Universidad Paris-Ouest Nanterre La Défense, Master en Derecho de la Propiedad Intelectual en el CEIPI de la Universidad de Estrasburgo.

Resumen: El Tribunal de Justicia de la Comunidad Andina ha venido elaborando una línea jurisprudencial coherente respecto a las marcas de colores. El órgano jurisdiccional supranacional ha desarrollado criterios para la aplicación de las diferentes causales de irregistrabilidad por falta de distintividad intrínseca del signo solicitado a registro conformado por una combinación de colores o un color específico delimitado por una forma determinada. Sin embargo, el Tribunal de Justicia de la Comunidad Andina se pronunció recientemente, contradiciendo el sentido de la referida línea jurisprudencial previa, a propósito de una controversia en relación con la interpretación del requisito relativo a que un signo consistente en un color aisladamente considerado se encuentre delimitado por una forma específica, establecido en los Artículos 134 Literal e) y 135 Literal h) de la Decisión 486, "Régimen Común sobre Propiedad Industrial" de la Comunidad Andina.

Palabras clave: Comunidad Andina, marcas de colores, combinaciones de colores, funcionalidad, genericidad, uso común.

\begin{abstract}
The Andean Court of Justice has been developing a consistent jurisprudential line with regard to colour trademarks. The supranational court has developed criteria for the application of the causes of non-registrability due to lack of intrinsic distinctiveness of the sign requested for registration consisting of a combination of colours or a specific colour delimited by a particular form. However, the Andean Court of Justice recently ruled, contradicting the essence of the aforementioned jurisprudential line, in a dispute regarding the interpretation of the requirement that a sign consisting of an isolated colour must be delimited by a specific form, established in Articles 134 e) and 135 b) of Decision 486, "Common Regime on Industrial Property" of the Andean Community.
\end{abstract}

Keywords: Andean Community, colour trademarks, colour combinations, functionality, genericity, common use.

1 Artículo enviado el 16.01.2020 y aceptado el 09.06.2020.

Número de página no utilizable para citar 
El tratamiento de las marcas de colores en la jurisprudencia del Tribunal de Justicia de la Comunidad Andina Juan Manuel Indacochea Jauregui

\section{Introducción}

A propósito de los 50 años de la Comunidad Andina ${ }^{2}$ y los 40 años del Tribunal de Justicia de la Comunidad Andina (en adelante, TJCA) ${ }^{3}$, resulta oportuno destacar la labor de este órgano jurisdiccional de carácter supranacional que, en el marco de su función de declarar el derecho comunitario, ha pronunciado más de 5000 fallos hasta la actualidad sobre diversa índole ${ }^{4}$. Entre la vasta temática abordada por el TJCA, cabe mencionar el comercio internacional, la libre competencia, la valoración aduanera, la doble imposición en materia tributaria, la seguridad y salud en el trabajo, el transporte internacional -intracomunitario- de pasajeros y mercancías, la libertad de expresión de los consumidores, la minería ilegal, la interconexión de redes telefónicas, la propiedad intelectual e industrial, entre otras materias.

A este respecto, es preciso indicar que el órgano jurisdiccional comunitario ha venido interpretando principalmente el articulado que conforma el "Régimen Común sobre Propiedad Industrial" (Decisión 486) ${ }^{5}$, en aras de su aplicación uniforme en el territorio de los países miembros. Entre las materias armonizadas destacan aquellas relativas a causales de irregistrabilidad por falta de distintividad intrínseca del signo solicitado a registro. Sin embargo, constantemente surgen nuevas controversias en relación con las marcas no convencionales o atípicas. $^{6}$

Las causales de irregistrabilidad - contenidas en la Decisión 486- referidas a signos o marcas no convencionales, en particular, aquellas relativas a las marcas de colores, han sido objeto de un vasto desarrollo jurisprudencial por parte del órgano jurisdiccional andino. Por ende, vale la pena dedicar el presente artículo al estudio de su jurisprudencia en materia de marcas de colores.

En la Decisión 486, las únicas referencias a las marcas de colores son, por un lado, la posibilidad de registrar marcas de colores en el sentido del Artículo 134 Literal e) ${ }^{7}$ y, por otro

2 Los Gobiernos de Bolivia, Colombia, Chile, Ecuador y Perú iniciaron el proceso andino de integración mediante la celebración del Acuerdo de Integración Subregional Andino (“Acuerdo de Cartagena") el 26 de mayo de 1969 en Cartagena, Colombia. En 1976, Chile se retiró del entonces denominado Pacto Andino, reincorporándose como miembro asociado en 2006.

3 El instrumento por el cual se estableció el TJCA es el "Tratado de Creación del Tribunal de Justicia del Acuerdo de Cartagena", firmado el 28 de mayo de 1979 en Cartagena, Colombia. Inició actividades en 1984. Se modificó su nombre mediante el Protocolo Modificatorio del Acuerdo de Integración Subregional Andino (Acuerdo de Cartagena), "Protocolo de Trujillo", suscrito el 10 de marzo de 1996 en Trujillo, Perú.

4 TJCA (Secretaría). "Procesos ingresados y aprobados por el TJCA desde 1984 al AJ 11 de 03/06/2019", documento inédito.

5 Decisión 486 de la Comisión de la Comunidad Andina, "Régimen Común sobre Propiedad Industrial”, publicada en la Gaceta Oficial del Acuerdo de Cartagena N 600 de 19 de setiembre de 2000, vigente a partir de 1 de diciembre de 2000.

6 Véase al respecto, Indacochea, Juan Manuel. "Marcas no convencionales, no tradicionales, atípicas o simplemente nuevos tipos de marcas", Ius Inter Gentes, Año 11, N 11 (2015): 141-164.

7 Decisión 486 de la Comisión de la Comunidad Andina. -

Número de página no utilizable para citar 
lado, la proscripción de registro contenida en el Artículo 135 Literal h) ${ }^{8}$, la cual determina la irregistrabilidad de signos que "consistan en un color aisladamente considerado, sin que se encuentre delimitado por una forma especifica”. En efecto, mientras que el Artículo 134 enumera de manera meramente ilustrativa -ad exemplum-algunos ejemplos de signos susceptibles de constituir marcas protegidas de conformidad con la Decisión 486 ("Podrán constituir marcas, entre otros, los siguientes signos"), el Artículo 135 establece por el contrario una enumeración cerrada -numerus clausus - de causales de irregistrabilidad por falta de distintividad intrínseca del signo solicitado a registro.

De conformidad con lo establecido en el Artículo 134 Literal e) de la Decisión 486, pueden constituir marcas protegidas en los países miembros de la Comunidad Andina, entre otros, “un color delimitado por una forma, o una combinación de colores". Vale decir, el "Régimen Común sobre Propiedad Industrial" permite el registro de marcas consistentes en un color específico, siempre que se encuentre delimitado por una forma específica. Asimismo, admite la protección de combinaciones de colores, es decir, de paletas de colores que, combinados según una secuencia u orden determinado, son susceptibles de conformar un signo con suficiente aptitud distintiva.

En otras palabras, la normativa andina permite el registro de marcas consistentes en un color específico debidamente delimitado por una forma particular que conjuntamente confieran carácter distintivo al conjunto marcario; así como de marcas conformadas por combinaciones de colores, que suponen el ensamblaje de varios colores según un orden determinado y de acuerdo con cierta composición (marcos, cuadros, etc.). ${ }^{9}$

En lo correspondiente a la jurisprudencia comunitaria, el TJCA elaboró una línea jurisprudencial coherente y uniforme respecto a las marcas de colores. Sin embargo, en virtud de la práctica registral de la Superintendencia de Industria y Comercio (en adelante, SIC) de Colombia, el órgano jurisdiccional de la CAN se pronunció recientemente contrariando el sentido de la línea jurisprudencial previamente elaborada, a propósito de una controversia en

Artículo 134.- A efectos de este régimen constituirá marca cualquier signo que sea apto para distinguir productos o servicios en el mercado. Podrán registrarse como marcas los signos susceptibles de representación gráfica. La naturaleza del producto o servicio al cual se ha de aplicar una marca en ningún caso será obstáculo para su registro.

Podrán constituir marcas, entre otros, los siguientes signos:

$[\ldots]$

e) un color delimitado por una forma, o una combinación de colores;

$[\ldots]$.

8 Decisión 486 de la Comisión de la Comunidad Andina. -

Artículo 135.- No podrán registrarse como marcas los signos que:

$[\ldots]$

h) consistan en un color aisladamente considerado, sin que se encuentre delimitado por una forma específica; $[\ldots]$.

9 Véase al respecto, la definición de los conceptos de "combinación”, "tonalidad” y "disposición” de colores según el derecho francés, WIPO. "Contribution de la France sur les nouveaux types de marques", SCT 17, pp. 3-4, disponible en: https://www.wipo.int/export/sites/www/sct/en/comments/pdf/sct17/fr_1.pdf. 
El tratamiento de las marcas de colores en la jurisprudencia del Tribunal de Justicia de la Comunidad Andina Juan Manuel Indacochea Jauregui

relación con el requisito - causal de irregistrabilidad- establecido en los Artículos 134 Literal e) y 135 Literal h) de la Decisión 486, es decir, aquel relativo al registro de signos constituidos por un único color aisladamente considerado: "que se encuentre delimitado por una forma especifica".

Sobre la base de la naturaleza de los casos conocidos por el órgano jurisdiccional comunitario en relación con las marcas de colores, el presente estudio, en primer lugar, analizará la línea jurisprudencial elaborada a través del mecanismo comunitario de la interpretación prejudicial; y, en segundo lugar, se concentrará en la sentencia recaída en el marco de una acción de incumplimiento en contra de la República de Colombia, formulada en virtud de la práctica registral de la SIC en torno al requisito de que los colores aisladamente considerados se encuentren delimitados por una forma específica, por resultar contradictoria con la jurisprudencial previamente elaborada por el TJCA mediante interpretaciones prejudiciales.

\section{La línea jurisprudencial elaborada a través del mecanismo de la interpretación prejudicial}

De conformidad con el Artículo 32 del Tratado de Creación del TJCA ${ }^{10}$ y el Artículo 121 de su Estatuto $^{11}$, la interpretación prejudicial tiene como fin "asegurar su aplicación uniforme en el territorio de los Países Miembros". En tal virtud, Manuel Pachón sostiene lo siguiente: "la piedra angular de la Comunidad [...] no es sólo una misma norma común, sino que dicha norma sea interpretada y aplicada de igual manera en toda la extensión de un mismo territorio por los Tribunales de todos los estados miembros" (Pachón, 1992: 76). De esta manera, mediante el mecanismo comunitario de la interpretación prejudicial, el órgano jurisdiccional andino elaboró una línea jurisprudencial uniforme en relación con las marcas de colores, conservando siempre un mismo criterio jurídico.Desde la temprana interpretación prejudicial recaída en el marco del Proceso 23-IP-98 de 25 de septiembre de $1998^{12}$, ya se explicaba el alcance de la prohibición de registro -causal de irregistrabilidad- de signos que "[c]onsistan en un color aisladamente considerado, sin que se encuentre

10 Tratado de Creación del Tribunal de Justicia de la Comunidad Andina, codificado por la Decisión 472 de la Comisión, publicado en la Gaceta Oficial del Acuerdo de Cartagena N 483 del 17 de setiembre de 1999.

“Artículo 32.- Corresponderá al Tribunal interpretar por vía prejudicial las normas que conforman el ordenamiento jurídico de la Comunidad Andina, con el fin de asegurar su aplicación uniforme en el territorio de los Países Miembros."

11 Estatuto del Tribunal de Justicia de la Comunidad Andina, aprobado por la Decisión 500 del Consejo Andino de Ministros de Relaciones Exteriores, publicado en la Gaceta Oficial del Acuerdo de Cartagena No 680 del 28 de junio de 2001. "Artículo 121.- Objeto y finalidad. - Corresponde al Tribunal interpretar las normas que conforman el ordenamiento jurídico de la Comunidad Andina, con el fin de asegurar su aplicación uniforme en el territorio de los Países Miembros."

12 TJCA. Interpretación prejudicial recaída en el Proceso 23-IP-98 (Tema II: "Prohibición de registro de colores") de 25 de septiembre de 1998, publicado en la Gaceta Oficial del Acuerdo de Cartagena No 379 de 27 de octubre de 1998, p. 6 (marca: "una cacha de machete y una denominación y colores"), disponible en: http://www.comunidadandina.org/DocOficialesFiles/Gacetas/gace379.pdf.

Número de página no utilizable para citar 
delimitado por una forma especifica", contenida en el Artículo 82 Literal f) de la Decisión 344 ${ }^{13}$, la cual precedió a la Decisión 486 como "Régimen Común sobre Propiedad Intelectual”.En el mencionado fallo se citó a Carlos Fernández-Novoa al advertir sobre los efectos anticompetitivos de la apropiación de un color puro afirmando que el titular "obtendría una ventaja competitiva desmesurada $y$, al mismo tiempo, los competidores tropezarian con un grave obstáculo que podría llegar a bloquear el libre acceso al mercado". Se advertía asimismo que los "efectos obstruccionistas" derivados de la concesión de un color puro "serían particularmente palpables en la bipótesis de que el color fuese necesariamente común a un género o línea de productos o a su envoltorio o envase" (Fernández - Novoa, 1990: 100).

A este respecto, el entonces Tribunal de Justicia de las Comunidades Europeas (ahora Tribunal de Justicia de la Unión Europea), en su Sentencia de 6 de mayo de 2003 recaída en el caso Libertel consideró que: "Los consumidores no están acostumbrados a deducir el origen de los productos sobre la base de su color o el de su envase, al margen de todo elemento gráfico o textual, puesto que, en principio, un color por sí solo no se emplea, en la práctica comercial actual, como medio de identificación."14

En el derecho comparado, el registro exitoso de marcas consistentes en un único color sin forma, marco, bordes, contornos u otros elementos generalmente se da gracias a la figura de la distintividad adquirida o sobrevenida ("acquired distinctiveness" o "secondary meaning" respecto, se puede citar, por ejemplo, el registro como marca del morado (Pantone $2685 \mathrm{C}$ ) de la barra del chocolate Dairy Milk de Cadbury -usado desde 1914 - en Nueva Zelanda ${ }^{16}$, de otra tonalidad de morado ("Whiskas Purple") en Australia" ${ }^{17}$, de una tonalidad de verde (Pantone 347 MC) en Suiza ${ }^{18}$, de una tonalidad especial verde-oro en Estados Unidos ${ }^{19}$ y de la suela roja

13 Decisión 344 de la Comisión del Acuerdo de Cartagena, "Régimen Común sobre Propiedad Industrial", publicada en la Gaceta Oficial del Acuerdo de Cartagena No 142 de 29 de octubre de 1993, vigente a partir de 1 de enero de 1994 hasta el 30 de noviembre de 2000.

Artículo 82.- No podrán registrarse como marcas los signos que:

$[\ldots]$

f) Consistan en un color aisladamente considerado, sin que se encuentre delimitado por una forma específica; [...]

14 TJCE. Sentencia de 6 de mayo de 2003, Libertel Groep BV c. Benelux Merkenbureau, asunto C-104/01, apartado 65.

15 En Estados Unidos, por ejemplo, es el principio de adquisición del derecho de marca por el uso el que rige en primer lugar. Cf. Piotraut, Jean-Luc. "La propriété intellectuelle en droit international et comparé (France, Allemagne, RoyaumeUni, Etats-Unis)". París: Lavoisier, 2007, p. 75.

16 Cadbury Ltd c. JH Whittaker \& Sons Ltd, caso No T26/2004, Comisionado Adjunto de Nueva Zelanda (IPONZ), 14 de noviembre de 2004. Véase también, Trademark Reporter, INTA, "13th Annual International Review of Trademark Jurisprudence”, marzo-abril de 2006, volumen 96, número 2, pp. 488 y 489.

17 Mars Australia Pty Ltd (anteriormente Effem Foods Pty Ltd) c. Société des Produits Nestlé SA, [2010] FCA 639, 22 de junio de 2010.

18 Registro 499 949, consistente en el color verde PANTONE 347 MC para distinguir productos comprendidos en la Clase 16 de la Clasificación Internacional de Niza. Se acreditó la adquisición de la distintividad sobrevenida por medio de una encuesta entre los consumidores.

19 En Qualitex Co. c. Jacobson Products Co., la Corte Suprema de Estados Unidos determinó por decisión unánime que "una tonalidad especial de verde-oro" ("a special shade of green-gold") cumple la función de marca para distinguir almohadillas de limpieza en seco, estableciendo además que para que un color pueda ser registrable como marca no debe ser funcional ("non functional") y debe haber adquirido distintividad de manera sobrevenida. Cf. Qualitex Co. c. Jacobson Products Co., Inc., 514 US. 159, 34 USPQ.2d 1161. 
El tratamiento de las marcas de colores en la jurisprudencia del Tribunal de Justicia de la Comunidad Andina Juan Manuel Indacochea Jauregui

(Pantone 181663 TP) de los zapatos taco aguja de Christian Louboutin ${ }^{20}$.A este respecto, es preciso tener en consideración que el párrafo final del Artículo $135^{21}$ de la Decisión 486 recoge la figura de la distintividad adquirida o sobrevenida. Por consiguiente, tanto un color aisladamente considerado no delimitado por forma alguna como un color debidamente circunscrito en una forma específica pero que incurra en alguna otra de las causales de irregistrabilidad por falta de distintividad intrínseca (e.g. color de uso común, descriptivo, genérico, necesario o funcional), podría acceder al registro al haber adquirido distintividad sobrevenida o un significado secundario (secondary meaning) en virtud de su uso constante en el país miembro correspondiente.

En la precitada interpretación prejudicial pronunciada en el marco del Proceso 23-IP-98, el órgano jurisdiccional de la Comunidad Andina explicó asimismo el alcance de la causal de irregistrabilidad prescrita en el Artículo 82 Literal f) de la anterior Decisión 344, actualmente contemplada en el Artículo 135 Literal h) de la Decisión 486: ${ }^{22}$

"Sin embargo, debe tenerse en cuenta que la prohibición bajo análisis no es absoluta, pues ella sólo opera cuando el color no se encuentra "delimitado por una forma específica”, es decir que cuando el mismo se encuentra comprendido en una silueta o trazo puede acceder al registro como marca, al igual que cuando hace parte integrante de un signo tridimensional, obviamente, siempre que éste no caiga en alguna otra causal de irregistrabilidad, pues, v. gr., no por el hecho de que la forma usual del producto sea la que delimite al color de que se trate, puede afirmarse su registrabilidad." (Subrayado agregado).

Los extractos transcritos de la interpretación prejudicial recaída en el Proceso 23-IP-98 fueron reiterados en la interpretación prejudicial recaída en el Proceso 111-IP-2009 ${ }^{23}$, la cual es citada a su vez por numerosas interpretaciones prejudiciales, entre las cuales es posible mencionar las pronunciadas en el marco de los Procesos 132-IP-2012 $2^{24}$, 147-IP-2013 ${ }^{25}$, 222-IP-2013 ${ }^{26}$ y 232-

20 TJUE. Sentencia de 12 de junio de 2018, Christian Louboutin SAS c. Van Haren Schoenen BV, asunto C-163/16.

21 Decisión 486 de la Comisión de la Comunidad Andina.-

Artículo 135.- No podrán registrarse como marcas los signos que:

$[\ldots]$

No obstante lo previsto en los literales b), e), f), g) y h), un signo podrá ser registrado como marca si quien solicita el registro o su causante lo hubiese estado usando constantemente en el País Miembro y, por efecto de tal uso, el signo ha adquirido aptitud distintiva respecto de los productos o servicios a los cuales se aplica.

22 TJCA. Interpretación prejudicial recaída en el Proceso 23-IP-98 (Tema II: "Prohibición de registro de colores") de 25 de septiembre de 1998, pp. 6-7.

23 TJCA. Interpretación prejudicial recaída en el Proceso 111-IP-2009 (Tema 3: "Prohibición de registro de colores") de 2 de diciembre de 2009, publicado en la Gaceta Oficial del Acuerdo de Cartagena No 1809 de 22 de marzo de 2010, pp. 3-4, disponible en: http://www.comunidadandina.org/DocOficialesFiles/Gacetas/Gace1809.pdf.

24 TJCA. Interpretación prejudicial recaída en el Proceso 136-IP-2012 (Tema 2: Registro de un color delimitado por la forma") de 3 de diciembre de 2012, publicada en la Gaceta Oficial del Acuerdo de Cartagena $\mathrm{N}^{\circ} 2168$ de 18 de marzo de 2013, p. 5, disponible en: http://www.comunidadandina.org/DocOficialesFiles/Gacetas/Gace2168.pdf.

25 TJCA. Interpretación prejudicial recaída en el Proceso 147-IP-2013 (Tema 2: "Registro de un color delimitado por una forma") de 20 de noviembre de 2013, publicada en la Gaceta Oficial de Acuerdo de Cartagena $\mathrm{N}^{\circ} 2304$ de 24 de febrero de 2014, p. 7, disponible en: http://www.comunidadandina.org/DocOficialesFiles/Gacetas/GACE2304.pdf.

Número de página no utilizable para citar 
IP-2016 ${ }^{27}$. Sin embargo, la interpretación prejudicial dictada en el Proceso 23-IP-98 agregaba lo siguiente en relación con la "marca compuesta de varios colores": "Ciertamente, una marca compuesta de varios colores debe tener el mismo tratamiento que se ha dispuesto para los signos genéricos o descriptivos, y por tanto, si analizados en conjunto proporcionan distintividad pueden ser registrados como marca." 28

Por su parte, la interpretación prejudicial recaída en el marco del Proceso 222-IP-2013 ${ }^{29}$ estableció ciertos parámetros referidos al registro de combinaciones de colores al señalar que los colores que conforman la combinación -solicitada a registro- deben encontrarse dispuestos y "representado [s] con contornos y trazos" de manera que "permitan hacer una reproducción del signo de una manera estable" y generen recordación respecto de su origen empresarial, confiriendo de esta manera distintividad al signo. Asimismo, se estableció que la disposición (unión) de estos colores debe ser "única, diferenciada y arbitraria". Cabe señalar que los mencionados criterios jurisprudenciales relativos al registro -como marca- de una combinación de colores fueron reiterados en la interpretación prejudicial recaída en el Proceso 53-IP-2015. ${ }^{30}$ Además de la causal de irregistrabilidad relativa a signos consistentes en un color aisladamente considerado sin que se encuentre delimitado por una forma específica (Artículo 135 Literal h) de la Decisión 486), es necesario que el signo solicitado - en su conjunto- no incurra en ninguna de las demás causales de irregistrabilidad, en particular aquellas relacionadas con la aptitud distintiva intrínseca del signo.En otras palabras, a efectos de su registro como marca, no basta que el signo solicitado conformado por una determinada tonalidad de color se encuentre delimitado por una forma específica, sino que el signo en su conjunto deberá contar además con distintividad intrínseca. Por ejemplo, no podrá tratarse de un color ni de una forma que puedan ser considerados como elementos de uso común, descriptivos, genéricos, necesarios o funcionales (i.e. que otorguen "una ventaja funcional o técnica al producto o al servicio al cual se aplican”). ${ }^{31} \mathrm{~A}$ este respecto, es importante destacar que el análisis que se realice, con ocasión del

26 TJCA. Interpretación prejudicial recaída en el Proceso 222-IP-2013 (Tema E: "Los colores y el registro marcario. La combinación de colores.") de 14 de mayo de 2014, publicada en la Gaceta Oficial del Acuerdo de Cartagena N 2353 de 16 de junio de 2014, p. 18, disponible en: http://www.comunidadandina.org/DocOficialesFiles/Gacetas/GACE2353.pdf.

27 TJCA. Interpretación prejudicial recaída en el Proceso 232-IP-2016 (Tema 4: "Registro de un color delimitado por la forma") de 11 de mayo de 2018, publicada en la Gaceta Oficial de Acuerdo de Cartagena № 3314 de 14 de junio de 2018, pp. 7-8, disponible en: http://www.comunidadandina.org/DocOficialesFiles/Gacetas/Gaceta\%203314.pdf.

28 TJCA. Interpretación prejudicial recaída en el Proceso 23-IP-98, p. 7.

29 TJCA. Interpretación prejudicial recaída en el Proceso 222-IP-2013, pp. 18-19.

30 TJCA. Interpretación prejudicial recaída en el Proceso 53-IP-2015 (Tema B: "Los colores y el registro de una marca. La combinación de colores.”) de 19 de agosto de 2015, publicada en la Gaceta Oficial del Acuerdo de Cartagena N 2590 de 5 de octubre de 2015, pp. 8-9, disponible en:

http://www.comunidadandina.org/DocOficialesFiles/Gacetas/GACE2590.pdf.

31 Decisión 486 de la Comisión de la Comunidad Andina. -

Artículo 135.- No podrán registrarse como marcas los signos que:

a) no puedan constituir marca conforme al primer párrafo del artículo anterior;

b) carezcan de distintividad;

c) consistan exclusivamente en formas usuales de los productos o de sus envases, o en formas o características impuestas por la naturaleza o la función de dicho producto o del servicio de que se trate;

Número de página no utilizable para citar 
El tratamiento de las marcas de colores en la jurisprudencia del Tribunal de Justicia de la Comunidad Andina Juan Manuel Indacochea Jauregui

examen de registrabilidad, a efectos de determinar el carácter distintivo intrínseco del signo solicitado a registro, debe efectuarse en función del producto o servicio que se pretende distinguir toda vez que un color o una forma podrían ser considerados como de uso común, descriptivos, genéricos, necesarios o funcionales en relación con una determinada clase internacional, mas no así respecto de otras.En tal virtud, en la interpretación prejudicial pronunciada en el marco del Proceso 232-IP-2015 el 2 de marzo de 2016 ${ }^{32}$, al desarrollar los Temas 7 y 8 intitulados "Elementos gráficos de uso común y descriptivos en la conformación de marcas mixtas (colores y figuras)" y "El principio de no funcionalidad aplicado a los colores", se brindaron ciertas pautas interpretativas a efectos de determinar si un color aisladamente considerado incurre en alguna de las mencionadas causales de irregistrabilidad por falta de distintividad instrínseca. De esta manera, en el párrafo 78 de la citada interpretación prejudicial, se mencionaron los siguientes ejemplos prácticos:

"En el caso de los colores de uso común, se pueden dar como ejemplos el color rojo para extintores de incendios y el amarillo para los servicios postales. En cuanto a colores descriptivos, es posible mencionar como ejemplos ilustrativos, el color amarillo para indicar el sabor a limón y el rosa para indicar el sabor de determinados productos, así como el color verde para pasa bocas o bocaditos con sabor a finas hierbas o cualquier color para distinguir tintes". (Subrayado agregado).

Es preciso destacar que la interpretación prejudicial 232-IP-2015 advierte expresamente que el color rosa es de uso común en relación con determinados productos. Sin embargo, las autoridades administrativas de los países miembros podrían no haber tomado en consideración la precitada interpretación prejudicial. Aun así, es importante señalar que en el mencionado fallo se cita a su vez la interpretación prejudicial recaída en el Proceso 23-IP-98, mencionada anteriormente, la cual comporta asimismo el inicio de la jurisprudencia referida a la doctrina de la funcionalidad. ${ }^{33}$

Es importante señalar que el precitado párrafo guarda correspondencia con el párrafo 87 de la interpretación prejudicial pronunciada en el marco del Proceso 232-IP-2015, el cual también desarrolló determinados aspectos de la doctrina de la funcionalidad aplicada a las marcas de colores, mencionando asimismo otros ejemplos prácticos: ${ }^{34}$

d) consistan exclusivamente en formas u otros elementos que den una ventaja funcional o técnica al producto o al servicio al cual se aplican; [...].

32 TJCA. Interpretación prejudicial recaída en el Proceso 232-IP-2015 de 2 de marzo de 2016, publicada en la Gaceta Oficial del Acuerdo de Cartagena $N^{\circ} 2737$ del 11 de mayo de 2016, pp. 24-31, disponible en: http://www.comunidadandina.org/DocOficialesFiles/Gacetas/GACE2737.pdf.

33 TJCA. Interpretación prejudicial recaída en el Proceso 23-IP-98, p.

34 TJCA. Interpretación prejudicial recaída en el Proceso 232-IP-2015, p. 29, párrafo 87.

Número de página no utilizable para citar 
"Se pueden citar como ejemplos de colores técnicamente funcionales con respecto al producto o servicio que distinguen, el color rojo para los extintores de incendios o ciertos colores para cables eléctricos. Adicionalmente, cabe indicar que existen colores que pueden tener una función utilitaria por poseer propiedades físicas o químicas tales como las de reflejar la luz o absorber el color. Finalmente, existen colores que cumplen una función económica, es decir, que son el resultado natural del proceso de fabricación, como el color terracota para tejas o piezas de cerámica."

El órgano jurisdiccional andino, en los párrafos precedentes de la precitada interpretación prejudicial emitida en el Proceso 232-IP-2015, aplicó la doctrina de la funcionalidad a las marcas de colores advirtiendo sobre la necesidad de que el signo -solicitado a registrocompuesto por un color funcional cuente además con otros elementos no cromáticos (gráficos, denominativos, tridimensionales, táctiles, etc.) que confieran aptitud distintiva al signo en su conjunto. Además, precisó que los colores funcionales contenidos en una marca no son oponibles frente a terceros, "por cuanto su inclusión dentro de una marca registrada no podrá conferir a su titular un derecho al uso exclusivo sobre el mismo". ${ }^{35}$

En su intento de armonizar las legislaciones internas de los países miembros, el órgano jurisdiccional comunitario procedió, en el párrafo 88 de la interpretación prejudicial recaída en el marco del Proceso 232-IP-2015, a enumerar de manera no exhaustiva -numerus apertus- los siguientes criterios, recogidos del derecho comparado, que deben tenerse en cuenta -entre otros- a efectos de determinar si un color es funcional: ${ }^{36}$

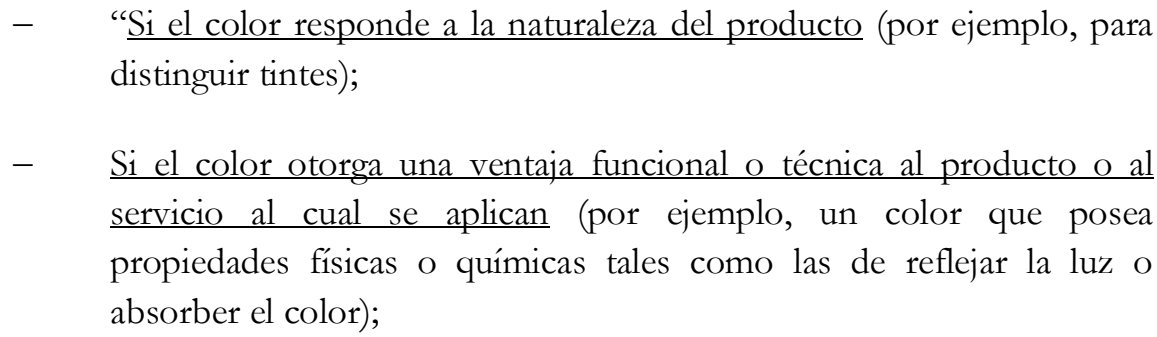

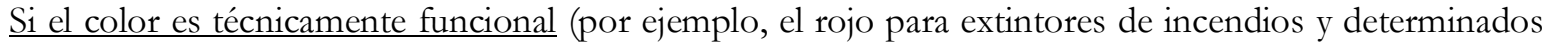

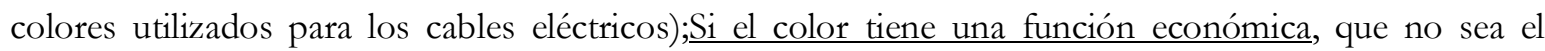
resultado natural del proceso de fabricación (como el color terracota para las tejas o las piezas de

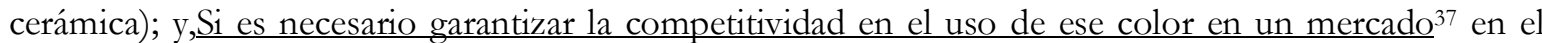

35 TJCA. Interpretación prejudicial recaída en el Proceso 232-IP-2015 p. 29, párrafo 84.

36 Los citados factores que deben tenerse en consideración a efectos de determinar la funcionalidad de un color respecto del producto o servicio al cual se aplica son reiterados en el "Pronunciamiento Octavo" de la interpretación prejudicial recaída en el Proceso 232-IP-2015, p. 34.

37 A este respecto, la interpretación prejudicial en el Proceso 232-IP-2015 hace referencia al apartado 56 de la Sentencia del Tribunal de Justicia de las Comunidades Europeas (TJCE) de 6 de mayo de 2003, asunto C-104/01, Libertel Groep BV c. Benelux-Merkenbureau. 
El tratamiento de las marcas de colores en la jurisprudencia del Tribunal de Justicia de la Comunidad Andina Juan Manuel Indacochea Jauregui

que, habida cuenta del color elegido y de los productos de que se trate, otros comerciantes con motivación suficiente recurrirán de modo natural a ese color y desearían utilizarlo de modo semejante para sus productos o servicios ${ }^{38}$." Es preciso indicar que la teoría de la funcionalidad ya había sido previamente desarrollada por el TJCA con ocasión de la interpretación prejudicial sobre la marca táctil o de textura, pronunciada el 4 de septiembre de 2015 en el marco del Proceso 242IP-2015". En la cuestión prejudicial $\mathrm{N}^{\circ} 5$ de dicho fallo, se abordó el tema relativo a "La textura impuesta por una función técnica o por la naturaleza del producto" a efectos de aplicar el requisito de no funcionalidad, contenido en los Literales c) y d) del Artículo 135 de la Decisión 486, a este tipo de marca no convencional.

El órgano jurisdiccional comunitario recogió la definición brindada por la Corte Suprema de Estados Unidos en el caso Qualitex, en el cual se estableció que un color es funcional desde el punto de vista jurídico cuando es esencial para alcanzar la finalidad del producto, para su uso o cuando afecta su calidad o costo. El TJCA, al igual que la Corte Suprema de Estados Unidos, precisó además que el criterio determinante en este caso es si el uso exclusivo del color -o característica funcional del producto- sitúa a los demás competidores en una posición de desventaja significativa. ${ }^{40}$

Adicionalmente, en el párrafo 137 de la interpretación prejudicial recaída en el Proceso 242-IP2015, el órgano jurisdiccional andino explicó textualmente lo siguiente: "la referencia a "la forma" del producto o de su envase, contenida en la precitada normativa andina, debe entenderse en sentido amplio, por el método de la ratio legis" ${ }^{\prime 4}$. En tal virtud, la referida causal de irregistrabilidad vinculada al requisito de no funcionalidad, contemplado en los Literales c) y d) del Artículo 135 de la Decisión 486 son igualmente aplicables a las marcas no convencionales, como las marcas de colores. $^{42}$

El registro de un signo que contenga un color funcional se deberá siempre a los demás elementos, denominativos (nominativos), figurativos (gráficos), tridimensionales (de forma), táctiles (de textura) o de cualquier otro tipo, que lo acompañen y confieran carácter distintivo

38 Los criterios establecidos responden a una interpretación sistemática del Artículo 135 Literales c) y d) de la Decisión 486, en concordancia con los criterios establecidos en las "Directrices de Examen de la Oficina de Armonización del Mercado Interno (OAMI)", Parte B: Examen. Sección 4: Motivos de denegación absolutos ("Guidelines for examination in the Office for Harmonization in the Internal Market" on community trademarks. Part B: Examination. Section 4: Absolute grounds for refusal), versión final 1.0, de 2 de enero de 2014, pp. 16-17; así como de la jurisprudencia comparada, especialmente, la reiterada por el Tribunal Federal de Australia en los casos Philmac Pty c. the Registrar Trademarks (2002) y BP Plc c. Woolworths Limited (2004), y la establecida por el TJCE en el caso Libertel (2003), asunto C-104/01.

39 TJCA. Interpretación prejudicial recaída en el Proceso 242-IP-2015, publicado en la Gaceta Oficial del Acuerdo de Cartagena $\mathrm{N}^{\circ} 2579$ de 4 de septiembre de 2015, disponible en: http://www.comunidadandina.org/DocOficialesFiles/Gacetas/GACE2579.pdf.

40 TJCA. Interpretación prejudicial recaída en el Proceso 242-IP-2015, p. 28, párrafo 129.

41 TJCA. Interpretación prejudicial recaída en el Proceso 242-IP-2015, p. 30, párrafo 137.

42 Véase, sobre la teoría de la funcionalidad en la referida jurisprudencia andina, Indacochea, Juan Manuel. "La interpretación prejudicial recaída en el Proceso 242-IP-2015 del Tribunal de Justicia de la Comunidad Andina”, Revista Tribuna Internacional, 7 (2018): $51-70$.

Número de página no utilizable para citar 
al signo en su conjunto. Ello implica a su vez la exclusión de tales elementos de un eventual cotejo de signos, lo cual es explicado de manera clara en el párrafo 91 de la interpretación prejudicial recaída en el Proceso 232-IP-2015:

"En consecuencia, en caso el cotejo entre signos distintivos involucre un signo que contenga elementos cromáticos funcionales, éstos deberán ser excluidos de la comparación y no podrán ser tenidos en cuenta para efectos de determinar la similitud entre los signos cotejados, por cuanto el alcance de la protección exclusiva no puede extenderse a elementos funcionales que otorguen una ventaja funcional o técnica al producto o servicio distinguido por el signo correspondiente, debiendo el titular de tal signo soportar el uso de colores funcionales idénticos o similares por parte de otros competidores, para distinguir los mismos productos o servicios."

La esencia de los mencionados criterios jurisprudenciales en relación con el uso común, la descriptividad, la genericidad, la necesidad o la funcionalidad de ciertos colores a efectos de distinguir determinados productos o servicios, fue recogida en la precitada interpretación prejudicial recaída en el Proceso 232-IP-2016: ${ }^{43}$

"Es posible el registro como marca de un color aislado si es que este se encuentra delimitado por una forma específica $y$, además, así visto en conjunto, y sin incurrir en otra causal de irregistrabilidad, goza de distintividad. Por tanto, el color no debe ser común a un género o línea de productos o a su envoltorio o envase, como tampoco ser característico de un determinado producto. Así, por ejemplo, los extintores son característicamente de color rojo. Para gozar de distintividad, el color no debe estar ligado a la naturaleza del producto de que se trate. El uso del color debe ser arbitrario, de modo que permita identificar el origen empresarial." (León y León, 2015: 173) (Subrayado agregado).

En consecuencia, la línea jurisprudencial previamente trazada por el órgano jurisdiccional comunitario no sólo recogía la doctrina de la funcionalidad sino incluso la había desarrollado al punto de brindar ejemplos prácticos en aras de proveer directrices tendientes a armonizar la aplicación de la normativa comunitaria por parte de las autoridades administrativas competentes de los países miembros. Además, la jurisprudencia andina parece haber sido clara respecto de la necesidad de que el signo solicitado no incurra en ninguna de las demás causales de irregistrabilidad por falta de distintividad intrínseca del signo adicionales a la funcionalidad, como son la ausencia de forma, el uso común, la descriptividad, la genericidad, la necesidad o la funcionalidad vis-à-vis la clase internacional -o género- de productos o servicios que se pretenden distinguir.

43 TJCA. Interpretación prejudicial recaída en el Proceso 232-IP-2016, p. 8, párrafo 1.5.

Número de página no utilizable para citar 


\section{La Sentencia pronunciada en el Proceso 1-AI-2017}

Como se explicó inicialmente, la práctica registral de la SIC conllevó a que el órgano jurisdiccional comunitario se pronuncie recientemente, en el marco del Proceso 1-AI-2017 ${ }^{44}$, sobre el requisito relativo a que los colores aisladamente considerados se encuentren delimitados por una forma específica. En efecto, como consta en los Memorandos 33-2019MP-TJCA de 16 de mayo de 2019 y 5-2019-MP-TJCA de 22 de enero de 2019, según afirmó la representante de Colombia en la audiencia pública celebrada el 20 de septiembre de 2018, de acuerdo al criterio y práctica registrales seguidos por la SIC: "la forma simplemente es para los fines de cumplir un requisito de orden administrativo" 45 .

El reclamo de la parte demandante (Acava Limited), se originó a raíz del otorgamiento, por parte de la SIC, de marcas que contienen el color rosado Pantone 183C, delimitadas por la forma de una botella ${ }^{46}$ y un vaso ${ }^{47}$, en favor de Gaseosas Posada Tobón S.A. (Postobón S.A.), así como del posterior reconocimiento de su notoriedad, que sirvió de fundamento para la denegatoria de registro del signo Big Cola Manzana ${ }^{48}$. Además, existiría la amenaza de que el referido titular plantee acciones por infracción de derechos de propiedad industrial en contra de terceros (RTD S.A.S. y Mercaderías S.A.S.) por el uso del color rosado para distinguir bebidas no alcohólicas con fundamento en la existencia de un riesgo de confusión con las mencionadas marcas. $^{49}$

La controversia principal, así como la posición de ambas partes, son explicadas de manera clara y concisa por el órgano jurisdiccional comunitario en el párrafo 134 de la Sentencia adoptada por mayoría: ${ }^{0}$ "En el caso concreto ACAVA LIMITED afirma que las marcas COLOR ROSADO Pantone 183C concedidas a favor de POSTOBÓN no eran aptas a registro al no encontrarse delimitadas por una forma distintiva, mientras que Colombia al responder el argumento de la demandante, enuncia que la forma no debe ser distintiva sino el color en sí”. En el párrafo 129 de la Sentencia, el TJCA consideró que: "En el presente caso, las Resoluciones adoptadas por la SIC no son actos que se opongan a lo regulado en la normatividad andina ni obstaculiza su aplicación, por el contrario, se

44 TJCA. Sentencia de 16 de mayo de 2019, pronunciada en el Proceso 1-AI-2017 (Acava Limited c. Colombia - SIC). Magistrada ponente: Cecilia Luisa Ayllón Quinteros (Bolivia). El voto disidente del Magistrado Hugo Ramiro Gómez Apac (Perú) consta como anexo del Memorando 33-2019-MP-TJCA de 16 de mayo de 2019.

45 Memorando 33-2019-MP-TJCA de 16 de mayo de 2019, p. 18; y, Memorando 5-2019-MP-TJCA de 22 de enero de 2019, p. 20.

46 Certificado 507285 otorgado en favor de Gaseosas Posada Tobón S.A. - Postobón S.A. para distinguir los siguientes productos comprendidos en la clase 32 "aguas minerales y gaseosas y otras bebidas no alcohólicas; sabor a manżana".

47 Certificado 507281 otorgado en favor de Gaseosas Posada Tobón S.A. - Postobón S.A. para distinguir los siguientes productos comprendidos en la clase 32 "aguas minerales y gaseosas y otras bebidas no alcohólicas; sabor a manzana".

48 TJCA. Sentencia de 16 de mayo de 2019, pronunciada en el Proceso 1-AI-2017 (Acava Limited c. Colombia - SIC). p. 8, párrafo 49.

49 TJCA. Sentencia de 16 de mayo de 2019, pronunciada en el Proceso 1-AI-2017, p. 3, párrafo 20.

50 TJCA. Sentencia de 16 de mayo de 2019, pronunciada en el Proceso 1-AI-2017, p. 23, párrafo 13

Número de página no utilizable para citar 
encuentra conforme a la misma y además acoge la interpretación de la norma realizada por el TJCA"51. De igual manera, en el párrafo 142 se pronunció de la siguiente manera: "Como se puede observar en el presente caso, el criterio jurídico adoptado por la SIC no es un acto que se oponga a lo regulado en la normatividad andina ni obstaculiza su aplicación"52. Así, el órgano jurisdiccional comunitario concluyó declarando, por mayoría, infundada en todos sus extremos la demanda de incumplimiento.Sin embargo, el entonces presidente del TJCA, el Magistrado Hugo Ramiro Gómez Apac, en el párrafo 5.18 del Memorando 33-2019-MP-TJCA, donde consta su voto disidente, en relación con el criterio jurídico aplicado en las resoluciones adoptadas por la SIC, sostuvo lo siguiente: "En las solicitudes solo analizaron el color. La SIC no hizo un análisis conjunto, que es lo exigido por la norma andina, lo que acredita el incumplimiento". 53

\section{Conclusiones}

La línea jurisprudencial anterior a la acción de incumplimiento, analizada en la primera parte del presente estudio, que puso de relieve la práctica registral de la SIC consistente en considerar la forma como un aspecto accesorio, secundario o meramente formal del signo solicitado a registro, establecía una directiva para las autoridades nacionales competentes de los países miembros de la Comunidad Andina.Sin embargo, con la sentencia recaída en la referida acción de incumplimiento planteada en contra de Colombia a causa de la controvertida práctica registral de la SIC se avala lo que justamente pretendía evitar la línea jurisprudencial anterior, es decir, que las autoridades competentes de los países miembros no tomen en consideración la forma a efectos del examen de registrabilidad del signo solicitado, en particular en lo concerniente al análisis de la distintividad intrínseca del signo en su conjunto.En virtud de que el registro como marca de un color aisladamente considerado comporta siempre una barrera al acceso al mercado para otros competidores, la normativa comunitaria exige que el color se encuentre delimitado por una forma específica susceptible de conferir la distintividad requerida al signo en su conjunto a efectos de su registro.

Finalmente, cabe destacar que la ausencia de forma no es la única causal de irregistrabilidad por falta de distintividad intrínseca del signo, sino que adicionalmente es preciso tener en consideración que el signo en su conjunto -el color delimitado por una forma específica- no debe ser de uso común, descriptivo, genérico, necesario ni funcional respecto a la clase internacional -o género- de productos o servicios a los que se aplique.

51 TJCA. Sentencia de 16 de mayo de 2019, pronunciada en el Proceso 1-AI-2017, p. 22, párrafo 129.

52 TJCA. Sentencia de 16 de mayo de 2019, pronunciada en el Proceso 1-AI-2017, p. 24, párrafo 142.

53 Memorando 33-2019-MP-TJCA de 16 de mayo de 2019, p. 27.

Número de página no utilizable para citar 
El tratamiento de las marcas de colores en la jurisprudencia del Tribunal de Justicia de la Comunidad Andina Juan Manuel Indacochea Jauregui

\section{Referencias Bibliográficas}

FERnÁndeZ-NovoA, Carlos (1990). Derecho de marcas. Madrid: Editorial Montecorvo, 1. ${ }^{a}$ ed.

LEÓn y LEÓn, Gustavo (2015). Derecho de Marcas en la Comunidad Andina. Lima: ECB Ediciones S.A.C., 1. ${ }^{\mathrm{a}}$ ed.

PACHÓN, Manuel (1992): "La acción de interpretación prejudicial en el Derecho Comunitario". En: THEMIS: Revista de Derecho 23. Lima: Asociación Civil THEMIS.

Número de página no utilizable para citar 